\title{
Os santos profanos - obscenidade e sagrado em Hilda Hilst e Georges Bataille
}

\author{
Aline Leal Fernandes Barbosa*
}

\begin{abstract}
RESUMO: Hilda Hilst e Georges Bataille encontram-se entre aqueles autores que, não raro, perseguiram o sagrado por vias do obsceno, operando um movimento que tem no corpo - e na sua profanação - uma via de acesso ao divino. Neste ensaio, a partir de algumas passagens dos textos e das trajetórias hilstianas e bataillianas, pretendemos apresentar momentos em que esses domínios se entrecruzam e se ultrapassam, marcados pela seguinte evolução: quanto mais se for obsceno, mais se será divino. Nesse sentido, estará em jogo a ideia de transgressão, em que os limites da existência descontínua serão atravessados em direção à experiência integrada do sagrado.
\end{abstract}

Palavras-chave: obsceno; sagrado; profano; Hilda Hilst; Georges Bataille.

Por que desfazer-se de Deus para refugiar-se em si mesmo? Por que essa substituição de cadáveres? Emil Cioran, Silogismos da amargura

Sentada, uma das pernas levantada, coxas afastadas, Madame Edwarda ${ }^{1}$ puxava a pele dos dois lados a fim de abrir a fenda ainda mais: "Assim, os trapos de Edwarda olhavam para mim, peludos e rosados, cheios de vida como um polvo repugnante". Em seguida, com a voz rouca, ela não hesita em afirmar: "veja, eu sou DEUS". A "chaga em carne viva" insiste desafiadoramente para que os olhos não se desviem: "Não, você tem que olhar: olhe!" (BATAILLE, 1981, p.82). Publicada em 1941, pela Éditions du Solitaire, sob o pseudônimo de Pierre Angélique, a novela batailliana narra a experiência angustiada e excitante do encontro entre um homem - o narrador - e a prostituta que dá nome ao título, marcada pela seguinte evolução: quanto mais Madame Edwarda for obscena, mais ela será divina. Deus-vulva-peluda, sol que atrai e ofusca, perturbadora imagem, entretanto irresistível: "não esquecerei jamais o que há de violento e maravilhoso no desejo de abrir os olhos, encarar de frente o que acontece, o que é. E eu nada saberei sobre o que acontece se nada souber sobre o prazer extremo e a extrema dor" (BATAILLE, 1981, p.10), afirma Bataille no prefácio a esta obra. A edição de 1956, editada pela Jean Jacques Pauvert ${ }^{2}$, contará com um prefácio do próprio Bataille, em que ele começa afirmando a gravidade do tema - da vida sexual, do prazer - e apontando para o contorno do sagrado nos temas da transgressão: "os tabus mais comuns incidem quer sobre a vida sexual, quer sobre a morte, de tal sorte que uma e outra formam um domínio sagrado, de cunho religioso" (BATAILLE, 1981, p.9).

Ora, que uma prostituta no ato de exibir a vagina se autoproclame Deus não escapa à reflexão que liga o obsceno ao sagrado, de fato é praticamente a imagem que condensa esta ideia. De modo que o obsceno, ao jogar $\operatorname{luz}^{3}$ sobre o que está relegado às sombras, ao revelar o segredo que excede o valor moral, segredo do qual temos medo, será um dispositivo de transgressão em direção à experiência integrada do sagrado, aquela que abarca em igual medida sua face nefasta e profana. E assim Madame Edwarda será profanada, sua santidade decaída na conjunção carnal:

Finalmente me ajoelhei, vacilante, e pousei meus lábios sobre a chaga em carne viva. A sua coxa acariciou a minha orelha: pareceu-me ouvir um ruído de mar pode-se escutar o mesmo barulho colocando uma concha grande contra o ouvido.” (BATAILLE, 1981, p.83).

Também em Hilda Hilst este cruzamento será amplamente explorado, a transgressão sacrílega em narrativas que invadem espaços a priori reservados quer ao universo do sagrado, quer ao universo do obsceno, realizando uma contaminação de 
esferas que se diriam opostas e que, entretanto, apresentam-se convergentes. Logo no início de Cartas de um sedutor (1990), terceiro livro da trilogia erótica hilstiana ${ }^{4}$, deparamo-nos com a seguinte consideração: "Deus? aqui ó, só sei de Deus quando entro na boca cabeluda da biriba" (HILST, 2013, p.139), frase que mira no ponto que une a santidade à sacanagem. Na seção "De outros ocos", Stamatius depara-se com o demônio nu, tristinho, de pau miúdo, e lhe pergunta: "por que teu pau é assim mirrado?", ao que o coisa-ruim responde: "desuso, meu caro", e, como tréplica: "não diga, sempre te associei a caralhos frementes", e em seguida: "não. Isso é Deus e o Lawrence, o D.H." (HILST, 2016, p.201). Mais adiante, Stamatius vai consolar Eulália, que acordara no meio da noite aos gritos de um sonho com o chifrudo, e então: "Então saio dos meios, da quentura, e de pau duro no meio da choça começo a gritar: sou Deus! sou Deus!” (HILST, 2016, p.202), blasfemando sem limites a figura divina bem como sua antípoda espiritual. E em um pequeno conto na seção Novos Antropofágicos, a respeito de uma ligação amorosa proibida entre um rapaz de 18 anos e uma bordadeira de 29, uma pequena fábula de iniciação sexual, somos apresentados à seguinte situação: "Antes de começar a chupá-la fiz o sinal da cruz, pedindo a Deus para ser aprovado naquela minha primeira prova. Fui. Gozou muitas vezes, e no gozo repetia Ai Jesus, ai Jesus" (HILST, 2016, p.213). E, tempos depois de desfeita a relação em virtude do flagrante da mãe, o rapaz segue com a lembrança, que dará o tom de fantasia a seus relacionamentos subsequentes: "Até hoje (passaram-se anos) só consigo o prazer ajoelhado diante da xiriba, fazendo o sinal da cruz e pedindo à parceira que repita várias vezes ai Jesus, ai Jesus" (HILST, 2013, p.214). De modo que o universo sexual será atravessado pelo universo sacro, e vice-versa, apostando na potência deste encontro que se dá na carne e que a supera no contato da ferida dos corpos: paixão de Cristo.

O sacrilégio será parte constituinte do sagrado, seu polo complementar e polo impuro privilegiado por Hilst ${ }^{5}$ e Bataille. Não se buscará, entretanto, o sagrado na ascensão de caráter transcendente, porém na exploração de sua parte terrena, provisória e imanente: será, sobretudo nos estados limítrofes da vida mundana, em seus momentos de exuberância e excentricidade, em que se divisarão os vislumbres de Deus. Ao final de Madame Edwarda, após uma elaboração a respeito do sentido - e da ausência de sentido - do ser, emenda-se com a seguinte proposição: "E DEUS? que podemos dizer a respeito, senhores Crentes? Será que pelo menos Ele sabe? DEUS, se soubesse, seria um porco*"6 (BATAILLE, 1981, p.94). Mais uma vez o símbolo do que é abjeto situa-se como lugar privilegiado para as revelações das fissuras da realidade, algo que está para além da realidade, mas que ao mesmo tempo a constitui ${ }^{7}$.

Para Henry Miller, autor que era para Hilda Hilst referência no tratamento do erótico, Deus e o obsceno serão estados cúmplices, uma vez que ultrapassam a medida da classificação. Assim começa seu ensaio "Obscenidade e Reflexão", escrito por ocasião da censura de seu Trópico de Câncer (1934): "Discutir a natureza e o sentido da obscenidade é quase tão difícil como falar de Deus" (MILLER, 1991, p.25). Do mesmo modo, se quisermos dizer o que significa o que Miller chama de "seis adjetivos mortais" - obsceno, lúbrico, lascivo, sujo, indecente, vergonhoso - seremos fracassados, porque escapam a uma existência controlada. Neste ensaio, o autor de cânones da literatura erótica atenta para a arbitrariedade da censura sobre o obsceno, tendo em vista seu caráter inclassificável, uma vez que nada seria obsceno em si, porém um efeito de determinada moralidade, e considerando a diversidade das obras potencialmente classificadas de eróticas, de Platão, Ovídio, Shakespeare às páginas da Bíblia. E será quase ao final deste ensaio que Miller oferecerá uma bela e poética paisagem do obsceno: 
Se há qualquer coisa que merece o nome de 'obsceno' é precisamente esta confrontação oblíqua de voyeur com os mistérios, esta marcha pelas bordas do abismo, com todos os êxtases da vertigem, ao mesmo tempo em que nos recusamos a abandonar a atração-encanto do desconhecido. O obsceno tem todos os requisitos da pausa que nos é subtraída. (MILLER, 1991, p.56-57)

Há, portanto, no obsceno um percorrer e ultrapassar determinado limiar - do que é privado, proibido, perigoso - e que irá conferir contorno ao desejo: a "atração-encanto" do desconhecido, o vazio da fabulação. Isso porque o perigo não apenas inibe como também excita o desejo. Trata-se, portanto, de uma experiência nas bordas do dizível e do inteligível, uma pausa, uma brecha das normas que contornam e corrigem. Pedro Alvim, no prefácio à edição portuguesa do ensaio de Miller, observa: "a obscenidade nos transcende à semelhança de Deus", e Eliane Robert Moraes, em "Excesso do excesso", apresentação do livro Das maravilhas e prodígios sexuais - a pornografia bizarra como entretenimento (2006), de Jorge Leite Jr., vai à mesma direção: "se a obscenidade aproxima-se do divino é porque ambos excedem o humano. Signos da 'obscura noite da alma', esses conhecimentos secretos permanecem interditados ao mundo social, só se desvelando ao preço de sua própria falsificação" (MORAES, 2006, p.11). Também Bataille vai tratar do tema da falsificação, da forma dissimulada de apresentação do erótico. No prefácio à Madame Edwarda, ele aponta: "O domínio do erotismo está condenado, sem escapatória, ao fingimento" (BATAILLE, 1981, p.13), isso porque, como a morte, está sempre desviado para o outro, eludido, pois fortemente deletéria será sua plena aproximação.

Além disso, o erotismo - como Deus, como a morte - por sua condição excessiva, será aquilo que não se pode fundamentar, que escapa à sua representação, de modo que a tentativa de representá-lo será imperfeita e rudimentar, uma tapeação diante de sua enormidade incontornável. E se é justamente nesses momentos - diga-se de passagem, insuportáveis - em que entramos mais intimamente em contato com o que há de mais genuíno em nosso ser, é preciso reconhecer que: "o ser nos é dado em um transbordamento intolerável do ser" (BATAILLE, 1981, p.12), apontando para uma intimidade exterior, ou uma exterioridade íntima. Sendo assim, serão testados os limites do indivíduo, de seu corpo, sua identidade, sua permanência, em uma reelaboração dos estatutos definidores do ser, sua separação concreta então vivida como experiência de dissolução e abandono, seu traço de acumulação como dispêndio. Bataille vai afirmar, em $O$ erotismo:

A obscenidade significa a desordem que perturba um estado dos corpos que estão conformes à posse de si, à posse da individualidade durável e afirmada. Há, ao contrário, desapossamento no jogo dos órgãos que se derramam no renovar da fusão, semelhante ao vaivém das ondas que se penetram e se perdem uma na outra. (BATAILLE, 1987, p.14)

Na obra batailliana e hilstiana não raro o corpo se apresentará como presença ostensiva, e ele aparece, sobretudo em desajuste e desatino, inconformado com sua forma e afeito a criar novas (im)possibilidades, apesar da angústia que acompanhará esse impulso subversivo. O corpo não é um fato dado e invisível do ser, muito pelo contrário, ele reclama, sofre, escarra, peida, arrota, goza: existe um corpo e ele quer se satisfazer. Impossível fazer dele pouco caso, simples contorno ou receptáculo, algo lhe escapa, como escapam nas narrativas hilstianas um gemido, uma frase dita como ato falho, uma palavra mais convulsiva, enveredando para diversos registros e materialidades. Como as narrativas hilstianas escapam a um gênero que lhes possa encerrar, como é de difícil classificação a obra de Bataille. E aí o corpo, que passava incólume como signo natural do homem, que 
estava alheio às suas manifestações, passa a ser um tema e um dilema. Além disso, serão as suas partes menos nobres, aquelas que soíam ficar ocultadas - o ânus, a vagina, o pênis, o dedão do pé - para onde estarão voltados os refletores.

E, como as possibilidades do corpo na fabulação parecem exceder aquelas que lhe reservam nosso real demarcado, o corpo humano pode, sem prestar contas, se metamorfosear em unicórnio ${ }^{8}$, enfiar um olho vagina adentro, ascender ou descender de seu estado material e profano. Mas o real guarda também surpresas e pode vez ou outra colocar-nos cara a cara com a cena aterrorizante do corpo degenerado, emprestando ao real aparência de ficção e ao corpo paisagens inimagináveis: as fotografias da execução do chinês Fou Chou $\mathrm{Li}^{9}$ e a tortura dos cem pedaços ${ }^{10}$ será, para Georges Bataille, algo como o encontro com o horror como disparador do pensamento sobre o suplício, a destruição, o dispêndio ilimitado. $\mathrm{O}$ horror que desestabiliza e nos mobiliza, como nos mobilizam o nojo e o asco.

Eliane Robert Moraes, em $O$ corpo impossível (2001), contextualiza o gesto estético destrutivo como resposta à crise do humanismo ocidental, entre o final do século XIX e a Segunda Guerra Mundial. A sensação de dispersão e instabilidade provocada pela vida moderna terá no corpo o alvo principal a ser atacado, sua integridade física feita em pedaços. Assim, ao artista moderno restava capturar os fragmentos desta época em seus instantes de presente: "A arte moderna respondeu à trama do caos através de formas fraturadas, estruturas parodísticas, justaposições inesperadas, registros de fluxos de consciência e da atmosfera da ambiguidade e ironia trágica que caracterizam tantas obras do período" (MORAES, 2001, p.57). Assim, se a experiência do indivíduo moderno caracteriza-se pela sua fragmentação, os movimentos que Bataille prioriza visam justamente restituir a fusão do homem com o mundo, recuperando sua inteireza, o que passaria pela experiência mística do sagrado.

Desse modo, a busca pela comunhão por meio de um ritual será também um gesto político, no sentido de restaurar a integralidade da experiência humana, que havia sido dissolvida pela modernidade, e poder agir no mundo, como Bataille indicou em L'apprentice de sorcier, texto que escreveu para a publicação oficial do College de Sociologie (1937/1939) ${ }^{11}$. A comunidade que Bataille havia fundado junto com Michel Leiris e Roger Caillois visava aliar pesquisa e militância em uma ideia de sociologia sagrada $^{12}$, em oposição à experiência fragmentada e controlada do indivíduo moderno. A comunidade Acéphale, por sua vez, que teve existência concomitante ao College, porém atuando de forma secreta, tinha pretensões de religião, mas dentro de uma mitologia votada à destruição e à morte de Deus, e, segundo reza a lenda, teria se dissolvido em razão da proposta - feita por Bataille - de realização de um sacrifício humano consentido, algo que jamais chegou a ocorrer. Tais experiências nas quais Bataille se engajou, em uma época em que a Europa vivia na iminência da segunda grande guerra ${ }^{13}$, foram, por alguns intelectuais, consideradas dotadas de conotações fascistas. Giorgio Agamben, no ensaio "Bataille e o paradoxo da soberania" (1987), conta a anedota que lhe fora relatada por Pierre Klossovski sobre seus encontros com Walter Benjamin, que, a respeito do grupo Acéphale e do ensaio batailliano "Sobre a noção de dispêndio", afirmava: "Vous travaillez pour le fascisme!" 14 . Ainda que esses movimentos fossem declaradamente anti-fascistas, Benjamin alertava sobre o perigo de se entrar em um jogo puro de "estetismo pré-fascista". Além disso, o fascínio com o ritual, o sacrifício e a comunidade soava por vezes, e para alguns, próximo aos regimes do fascismo.

Jean Paul Sartre, por sua vez, chamou Georges Bataille de "ateu místico", no ensaio "Um nouveau mystique", publicado em Cahiers du sud, em fevereiro de 1943. Aí Bataille é acusado de, em A experiência interior (1943), a que Sartre denomina ironicamente 
"ensaio mártir", introduzir a transcendência na imanência, de fundar uma religião sem Deus, ou de apoiar um Deus "como assombramento"15. Não espanta que o grande intelectual marxista da França no século XX se sentisse incomodado com um pensamento que aludisse ao sagrado, a uma economia do excesso e à valorização do instante presente em detrimento do tempo ulterior, sentindo aí cheiro de misticismo.

O sacrifício será o espetáculo de destruição dos corpos para o qual Bataille demonstrará particular interesse, contribuindo para elaborar a noção de sagrado ${ }^{16}$ que percorrerá toda a sua obra. Os ritos sacrificiais das antigas civilizações, sobretudo as mexicanas, e, em especial, o Potlatch ${ }^{17}$, das tribos do noroeste da América do Norte, como "poder de perder", serão privilegiados na medida em que o dispêndio ali praticado subverte a ordem da acumulação para a ordem do gasto improdutivo, criando uma suspensão das atividades produtivas em favor do jogo, da festa. De modo que se destaca, na sociedade humana, o "interesse em perdas consideráveis, em catástrofes que provoquem, de acordo com necessidades definidas, depressões tumultuosas, crises de angústia e, em última análise, um certo estado orgíaco" (BATAILLE, 2013, p.20).

Sabemos que também Hilda Hilst flertou com o sagrado intensamente. É notável que sua obra e sua vida lhe tenham sido permeáveis, no insistente esforço de interlocução com o divino, na busca de um contato mais pleno com a matéria essencial, ainda que em estado acidental, em sua disposição para uma sensibilidade extrema que pudesse alcançar o que o mundo real organizado recusa. Religiosa e profana, fortemente mística e atenta aos sinais deste e de outros mundos, do humano e de outros seres e manifestações, Hilda Hilst, figura insólita e avessa a convenções, apostava em uma concepção particular do sagrado, destituída de regras ou religiões, em que o homem transporia sua individualidade limitadora para uma comunicação intensa e extensiva. Em entrevista para o jornal Aqui, de São Paulo, em 1971, ela afirma:

\footnotetext{
Imagino que se o homem retomasse o sagrado das coisas, se ele olhasse cada coisa como se ela tivesse uma pulsação sagrada, se ele pudesse ver isso sem os termos da religiosidade ortodoxa, se ele pudesse ver o existir da planta, do ar, dos bichos, se de repente o homem pudesse observar o mundo com um certo fervor, sem essa religiosidade arrumada, se ele descesse ao poço, começaria a perceber sua íntima relação com tudo o que o cerca, e essa coisa faria ele retomar as coordenadas de sua alma. (SCWARTZKOPTT; HILST, 1971).
}

No prefácio à Madame Edwarda, Bataille vai afirmar: "Deus não é nada se não for um ultrapassar de Deus em todos os sentidos; no sentido do ser vulgar, no sentido do horror e da impureza e, finalmente, no sentido de nada" (BATAILLE, 1981, p.12). O sagrado será, assim, um dispositivo para se pensar o que não é possível nomear, o que incide no corpo e o questiona, a linguagem do excesso e do resíduo, da busca e da espera, do que se faz em silêncio e em nada.

A experiência do sagrado - no domínio sexual, nos ritos coletivos, na própria vida cotidiana -, a experiência mística de transbordamento, sua atmosfera extática de saída e perda de si, seu ideal de dispêndio em contradição aos empreendimentos de acumulação foram os condutores da reflexão que tencionamos abarcar neste artigo. Hilst e Bataille se interessaram por experiências fundamentais como o erotismo, o sagrado, a morte. Mas é importante ressaltar que esta empreitada está fadada ao fracasso, visto que o impossível é negado na medida dos limites intransponíveis do homem (ser limitado, descontínuo), legando à literatura - e ao escritor - o movimento vertiginoso entre o possível e o impossível. 


\section{The profane saints - obscenity and sacred in Hilda Hilst and Georges Bataille.}

ABSTRACT: Hilda Hilst and Georges Bataille are among those authors who have often pursued the sacred by means of the obscene, operating a movement that has in the body - and in its desecration - a way of accessing the divine. In this essay, from some passages of the Hilstian and Batallian texts and trajectories, we intend to present moments in which these domains intersect and exceed, marked by the following evolution: the more obscene, the more divine. In this sense, the idea of transgression will be at stake.

Keywords: Obscene. Sacred. Profane. Hilda Hilst. Georges Bataille.

\footnotetext{
* Doutora em Literatura, Cultura e Contemporaneidade pela PUC-Rio, professora da Central de Cursos de Extensão da PUC-Rio.

${ }^{1}$ Escrito sob o pseudônimo de Pierre Angélique, originalmente em 1941, com uma tiragem inicial de 50 exemplares, mais 50 em 1945, tinha um falso título em sua contracapa - Divinus Deus -, que seria o primeiro de uma trilogia, seguido por Ma mère e Charlotte d'Ingervilles. O manuscrito original de Madame Edwarda foi dedicado a Paul Eluard (1895-1952), poeta francês.

2 Jean-Jacques Pauvert (1926-2014) ficou conhecido por editar novos autores e obras consideradas marginais. Em 1945, com 20 anos de idade, editou oficialmente Juliettte, do então censurado Marquês de Sade, tirando sua obra da clandestinidade, o que lhe rendeu um processo que durou dez anos. Pauvert também ficou conhecido por ajudar a tornar a obra de Georges Bataille respeitada.

${ }^{3}$ No prefácio à História do olho, Bataille afirma: "Porém, se não fizermos incidir um foco de luz no ponto exato onde a noite cai, como poderemos saber que somos feitos da projeção do ser no horror?" (BATAILLE, 1981, p.13).
}

4 A trilogia mais tarde consolida-se como tetralogia, com a incorporação do livro de poemas Bufólicas (1992). No entanto, tendo em vista que o projeto original de Hilda Hilst consistia em uma trilogia, vamos tratá-la nestes termos, dando ênfase aos três primeiros livros: O caderno Rosa de Lori Lamby (1990), Contos d'escárnio, textos grotescos (1990) e Cartas de um sedutor (1991).

${ }^{5}$ No ensaio "A medida estilhaçada", publicado no Caderno de Literatura Brasileira (1999), do Instituto Moreira Salles, Eliane Robert Moraes aponta para o fato de que essa não foi inicialmente a apropriação do divino feita por Hilda Hilst, indicando que, em seu primeiro tempo como poeta, iniciado com Presságio (1950), a ideia de Deus supõe uma metafísica pura e imaterial. A mudança ocorreria em seu primeiro livro de prosa, Fluxo (1970), confrontando a ideia de Deus com o reino do perecível e do contingente.

${ }^{6}$ Esta nota em asterisco está contida no original e aparece no final do livro: “(*)Disse que Deus, se 'soubesse', seria um porco. Aquele que (suponho que estaria, no momento, mal lavado, 'despenteado') compreendesse até o fundo o que eu quero dizer, que dose de humanidade teria? além, e de tudo... mais longe, mais longe ainda... ELE PRÓPRIO, em êxtase sobre o vazio... E agora? ESTOU TREMENDO." (BATAILLE, 1981, p.95).

${ }^{7}$ Impossível não relacionar este ao Deus-porco de Hilda Hilst, que aparece na versão feminina - "a porca é Deus" - em Com os meus olhos de cão. Como forma de prece em Amavisse - "Senhor de porcos e de homens". Como personagem - Porco-menino - em A obscena senhora D, como aponta Eliane Robert Moraes no ensaio já citado "A medida estilhaçada".

${ }^{8}$ Aqui faz-se referência ao conto $O$ unicórnio, de Hilda Hilst, publicado em 1970 em Fluxo-floema, seu primeiro livro de contos.

${ }^{9}$ Georges Bataille dedica as últimas páginas de As lágrimas de Eros (1961), seu último livro publicado em vida, ao Suplício Chinês. Trata-se de uma série de fotografias, uma delas reproduzida em 1923 na revista Traité de Psychologie, de George Dumas, presenteada a Bataille em 1925 pelo psicanalista francês Adrian Borel. As quatro fotografias da série retratam o lingchi - a tortura dos cem pedaços - documentando o esquartejamento do jovem chinês Fou Chou Li, assassino do príncipe Ao-Han-Quan, no início do século XX, em Pequim.

${ }^{10}$ Embora Bataille se refira ao lingchi como a tortura dos "cem pedaços", na maioria das fontes que encontramos, o lingchi é referido como a tortura dos "mil cortes". O lingchi teria surgido na China durante a dinastia Tang (de 618 a 907) e tido curso até 1905, no final da dinastia Qing (de 1644 a 1912), quando então foi banido. A punição começava com prender o castigado em um tronco e ir fatiando sua pele pouco a pouco. A ideia era aplicar a maior quantidade de cortes possível antes de a pessoa perder a consciência ou sucumbir aos ferimentos. Em geral os cortes começavam pelo peito, onde a pele e os músculos eram meticulosamente removidos até que as costelas ficassem praticamente expostas. Depois, prosseguia-se para os braços e, por

IPOTESI, JUIZ DE FORA, v.21, n.2, p.27-34, jul./dez. 2017 
último, o foco passava a ser as coxas do executado. Fou Chou Li teria sido o último homem a ser executado por essa técnica, que teria sido abolida duas semanas depois da sua execução.

${ }^{11}$ Para uma compreensão mais aprofundada deste tema, ler ensaio "Georges Bataille, Michel Leiris e a experiência do sagrado no entreguerras" de Julia Vilaça Goyatá. Acessado em 10/05/2017: http://www.scielo.br/scielo.php?script=sci_arttext\&pid=S0100-85872014000200065\&lng=pt

${ }^{12}$ No número 3 e 4, de 1937, da revista Acéphale, em "Nota sobre a fundação de um colégio de sociologia", que transcrevemos aqui: "O objeto preciso da atividade visada pode receber o nome de sociologia sagrada, dado que ele implica o estudo da existência social em todas aquelas de suas manifestações em que vêm à luz a presença ativa do sagrado. Ela se propõe assim a estabelecer os pontos de coincidência entre as tendências obsedantes fundamentais da psicologia individual e as estruturas diretrizes que comandam suas revoluções" (Acéphale, vol. 3 e 4, p.28).

${ }^{13}$ Em 1933, Bataille publica "La structure psychologique du fascisme ", em La Critique Sociale, destinado a pensar a ascensão do fascismo. Neste ensaio, Bataille apresenta dois conceitos que atravessarão toda a sua obra, o de homogeneidade e o de heterogeneidade.

14 "Você trabalha para o fascismo!" Tradução nossa

${ }^{15}$ Encontramos esta expressão no ensaio de Françoise Meltzer "Sobre a questão da Aufhebung: Baudelaire, Bataille e Sartre" (2006), publicado no Brasil na Revista Crítica de Ciências Sociais. Acessado em 13/06/2017: https://rccs.revues.org/895

${ }^{16}$ Conceito adquirido do vocabulário antropológico a partir de sua leitura de Marcel Mauss, sobretudo de seu Ensaio sobre o dom, e advindo indiretamente de Émile Durkheim, em Les formes élémentaires de la vie religieuse (1912).

${ }^{17}$ De acordo como maior número de fontes consultadas, Potlatch em chinook quer dizer "presente" ou "ato de dar".

\section{REFERÊNCIAS}

BATAILLE, Georges. A história do olho - seguido de Madame Edwarda e O morto. Trad. Glória Correia Ramos. São Paulo: Editora e Livraria Escrita, 1981.

O erotismo. Trad. Antonio Carlos Viana. Porto Alegre: L\&PM, 1987.

L'érotisme. Paris : Les Éditions de Minuit, 2011.

A parte maldita - precedida de A noção de dispêndio. Trad. Fernando

Scheibe. Belo Horizonte: Autêntica, 2013.

A experiência interior seguida de Método de meditação e Postscriptum 1953.

Trad. Fernando Scheibe. Belo Horizonte: Autêntica, 2016.

CIORAN, Emil. Silogismos da amargura. Trad. José Thomaz Brum. Rio de Janeiro: Rocco, 2011.

GOYATÁ, Julia. "Georges Bataille, Michel Leiris e a experiência do sagrado no entreguerras". In: Relig. soc. [online]. 2014, vol.34, n.2, pp.65-85. ISSN 0100-8587. Disponível em (13/06/1984): http://dx.doi.org/10.1590/S1984-04382014000200004.

HILST, Hilda. Pornochic - O caderno rosa de Lori Lamby/Contos d'escárnio textos grotescos/ Cartas de um sedutor. São Paulo: Editora Globo, 2016.

Rútilo nada/ A obscena senhora D/ Qadós. Campinas: Pontes, 1993.

Fluxo-floema. São Paulo: Editora Globo, 2003.

IPOTESI, JUIZ DE FORA, v.21, n.2, p.27-34, jul./dez. 2017 
MELTZER, Françoise. "Sobre a questão da Aufhebung: Baudelaire, Bataille e Sartre". Revista Crítica de Ciências Sociais [Online], 75|2006, colocado online no dia 01 Outubro 2012, criado a 28 Junho 2017. URL : http://rccs.revues.org/895 ; DOI : 10.4000/rccs.895

MILLER, Henry. Trópico de câncer. Trad. Aydano Arruda. São Paulo: O Globo; Folha de São Paulo, 2003.

Obscenidade e reflexão. Trad. Pedro Alvim. Lisboa: Passagens, 1991.

MORAES, Eliane Robert. "Excesso do Excesso". In: LEITE JÚNIOR, Jorge. Das maravilhas e prodígios sexuais: a pornografia bizarra como entretenimento. São Paulo: Annablume, 2006.

O corpo impossível: a decomposição da figura humana: de Lautréamont a Bataille. São Paulo: Iluminuras, 2001.

SCWARTZKOPTT, H. Hilda Hilst: Perto do coração selvagem. Aqui, São Paulo, 10 a 16 de fevereiro, 1971 